\title{
Energy Harvesting and Remote Powering for Implantable Biosensors
}

\author{
Jacopo Olivo, Sandro Carrara, Member, IEEE, and Giovanni De Micheli, Fellow, IEEE
}

\begin{abstract}
This paper reviews some popular techniques to harvest energy for implantable biosensors. For each technique, the advantages and drawbacks are discussed. Emphasis is placed on the inductive links that are able to deliver power wirelessly through the biological tissues and enable bidirectional data communication with the implanted sensors. Finally, high-frequency inductive links are described, focusing also on the power absorbed by the tissues.
\end{abstract}

Index Terms-Energy harvesting, implantable biosensors, inductive powering, remote powering.

\section{INTRODUCTION}

$\mathbf{T}$ HESE days, there is an increasing interest in the field of implantable biosensors. The possibility of real-time monitoring of the human body from inside paves the way for a great number of applications and offers wide scenarios for the future.

A promising application is the use of implanted electrode arrays to monitor local neural circuits and the related spiking activity [1]-[4]. The study of brain neural activity is a great help in the treatment of disorders, such as blindness, deafness, epilepsy, Parkinson's disease, and paralysis. For instance, in the latter mentioned disorder, by observing the emission rate of electrical impulses occurring when particular movements are performed, it is possible to transform these signals in commands for neuroprosthetic devices. These devices, controlled directly by the thought through the nerve signals [5], are thus able to partially render the mobility to people with motion disabilities.

The brain is not the only application area for implantable biosensors; significant effort is dedicated to the design and development of implantable chemical sensors, capable of detecting the concentration of clinically relevant species [6] or to constantly monitor the health status by collecting biometric data to better calibrate therapy or to prevent dangerous events, such as hearth attacks or ictus.

Several key challenges must be addressed to realize these scenarios: implantable biosensors should be minimally invasive, completely biocompatible, and with low thermal dissipation [7]

\footnotetext{
Manuscript received July 21, 2010; revised September 17, 2010; accepted September 17, 2010. Date of publication October 07, 2010; date of current version May 20, 2011. This work was supported in part by the i-IronIC project and in part by the NanoSys project. The NanoSys project is within the program ERC-2009-AdG-246810. The i-IronIC project was financed by a grant from the Swiss Nano-Tera.ch initiative and evaluated by the Swiss National Science Foundation. The associate editor coordinating the review of this manuscript and approving it for publication was Prof. Evgeny Katz.

The authors are with the Integrated Systems Laboratory, École Polytechnique Fédérale de Lausanne, Lausanne 1015, Switzerland (e-mail: jacopo.olivo@epfl.ch; sandro.carrara@epfl.ch; giovanni.demicheli@epfl.ch).

Color versions of one or more of the figures in this paper are available online at http://ieeexplore.ieee.org.

Digital Object Identifier 10.1109/JSEN.2010.2085042
}

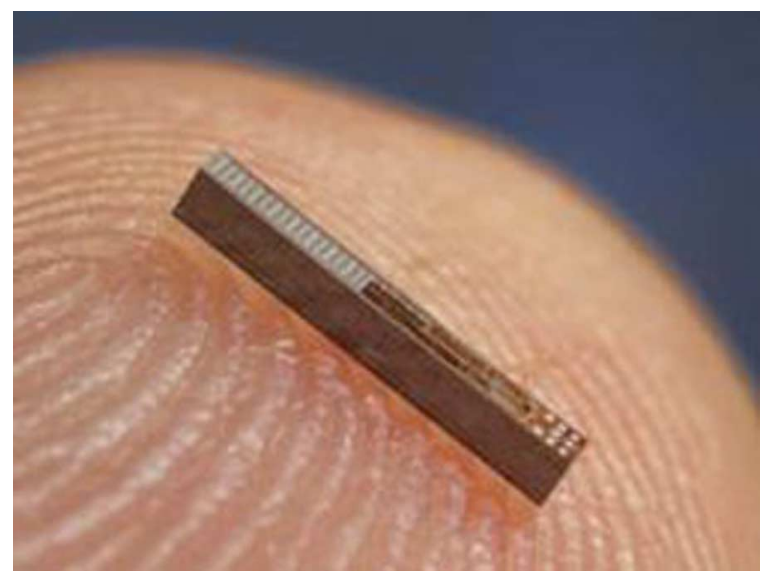

Fig. 1. Implantable sensor, having 1-mm diameter, to measure and monitor blood pressure. Image from [9].

and large power autonomy. In particular, this latter aspect must be carefully considered, since the performance of an implanted device depends on the power availability.

Modern batteries have increased capabilities with respect to those available in the past: for example, lithium-ion batteries have reached a high level of energy density (up to $0.2 \mathrm{Wh} / \mathrm{g}$ ) and are able to maintain an almost constant voltage until they are discharged to $75 \%-80 \%$ [8]. Unfortunately, size constraints of implantable batteries limit their efficiency, and their repeated use implies their substitution after a while.

Power constraints can be relaxed by energy harvesters, also called energy scavengers. These devices exploit natural or artificial power sources surrounding the person to assist the implanted batteries, to recharge them, and, in certain cases, even to replace them. Energy harvesters for implantable biosensors have been exhaustively studied and a large number of solutions for different cases can be found in the literature.

Most of the physical phenomena have been studied to obtain harvesters suitable for in-body applications, having minimum invasivity and high efficiency. This paper aims at reviewing some of these solutions, discussing the pros and cons, the related applications, and the potential of each solution. This paper is organized as follows. Section II discusses some of the most popular harvesting techniques for on-body and in-body applications. Section III describes, in detail, the use of inductive links for wireless remote powering of implanted devices. Finally, Section IV concludes this paper. The Appendix provides a brief introduction to the study of inductive links by means of scattering parameters. 


\section{HARVESTING AND REMOte POWERING TECHNIQUES}

In this section, some of the most popular harvesting techniques for implantable biosensors are discussed, presenting the advantages and disadvantages of each technique. The last paragraph of this section offers an outlook of some new emerging techniques inspired by the biological mechanisms.

\section{A. Kinetic}

Kinetic harvesters aim to collect the energy related to human motions and transform it into electrical energy [10]. These kinds of harvesters can be classified into three categories, depending on the employed transduction method: 1) electromagnetic; 2) electrostatic; and 3) piezoelectric.

Kinetic harvesters using electromagnetic transducers are able to generate an electromotive force due to the change of an external magnetic flux through a closed circuit. The change of flux can be induced, for instance, by rotating the circuit along an axis, thereby changing the surface associated with the magnetic flux.

This method has been used by Seiko to power the quartz wristwatch "Seiko Kinetic" [11]. This watch is able to selfcharge by the means of wrist motion, transmitted by an oscillating weight to a magnetic rotor linked to a coil [12]. The motion of the rotor induces an electromotive force through a coil, and the generated charge is stored in a common battery. Moreover, this harvester is equipped with a charge pump circuit with different multiplicative factors to quickly increase the voltage of the battery in order to reduce the startup time of the watch as much as possible.

The approach of Seiko has also been successfully tested in the biomedical field, being able to exploit the heartbeats to charge a pacemaker battery [13]. Implanted on a dog, this energy harvester has collected $80 \mathrm{~mJ}$ after $30 \mathrm{~min}$ with a cardiac frequency of about 200 beats/min: around $13 \mu \mathrm{J}$ per beat with a returned power of about $44 \mu \mathrm{W}$. A possible drawback of this technique is the necessity to periodically lubricate the moving parts which, in the end, need to be replaced when worn out. Moreover, the size of the oscillating weight makes this solution not suitable for low-invasive biosensors with small dimensions.

Kinetic harvesters based on electrostatic transducers utilize variable capacitors having the position of the plates changed by an external force. They can work with fixed charge or fixed voltage. Working with a fixed charge, the external force changes the voltage across the capacitor, while working with fixed potential, the motion of the plates generates current through the capacitor. Independent of the operation mode, in most cases, they need to be precharged to operate. This technique has low efficiency when high power is required, but works quite well with devices having low-power requirements, such as the implantable biosensors. Furthermore, it is appropriate for microelectromechanical-system (MEMS) realization.

The literature offers kinetic harvesters with electrostatic transducers that can render up to $58 \mu \mathrm{W}$ when set in motion by a force emulating the cardiac signal, exploiting a capacitor with a capacitance variable between $32 \mathrm{nF}$ and $110 \mathrm{nF}$ [14]. A MEMS electrostatic harvester rendering $80 \mu \mathrm{W}$ when excited with an acceleration of $10 \mathrm{~m} / \mathrm{s}^{2}$ has been proposed [15]. This

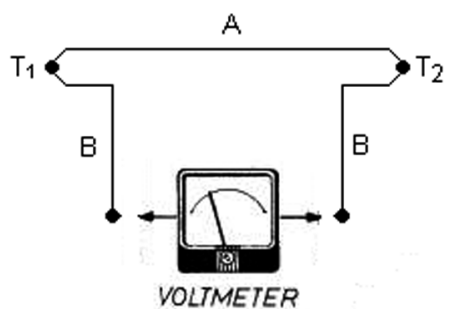

Fig. 2. Schematic representation of a thermocouple: two different materials are linked together, keeping their junctions at different temperatures. A voltage drop is thus created across them because of the Seebeck effect.

harvester is dedicated to biomedical applications and operates with constant charge. Moreover, it is nonresonant; thus, it can operate over a wide range of oscillation frequencies.

Finally, the kinetic harvesters based on piezoelectric transducers use the capability of the piezoelectric materials to generate an electric field when subjected to mechanical deformation. Different from the electrostatic transducers, no precharging is required. Piezoelectric harvesters based on aluminum nitride (AIN) have returned up to $60 \mu \mathrm{W}$, with a footprint smaller than $1 \mathrm{~cm}^{2}$ [16]; this power, however, is obtained with unpackaged devices and could significantly decrease once the harvesters are packaged. Piezoelectric harvesters based on lead zirconate titanate (PZT) have obtained up to $40 \mu \mathrm{W}$ [17].

Kinetic harvesters are widely used in commercial sensors available in the market. Perpetuum [18] and EnOcean [19] provide a large spectrum of solutions for different application fields, including wireless sensor nodes. None of these commercial solutions are, however, dedicated to implantable biosensors.

\section{B. Thermoelectric Effect}

Scavengers exploiting thermal gradients to generate energy are based on the Seebeck effect. Due to a temperature difference between two different metals or semiconductors, a voltage drop is created across them.

The core element of this kind of scavenger is the thermocouple (Fig. 2). Two materials are linked together, maintaining their junctions at different temperatures. The voltage generated across a thermocouple due to a temperature difference $\left(T_{1}-T_{2}\right)$ can be expressed as

$$
V=\int_{\mathrm{T}_{1}}^{T_{2}}\left[S_{\mathrm{B}}(T)-S_{\mathrm{A}}(T)\right] \mathrm{d} T
$$

where $S_{\mathrm{A}}$ and $S_{\mathrm{B}}$ are the thermoelectric powers (or Seebeck coefficients) of the two materials $A$ and $B$. Semiconductors typically have a high Seebeck coefficient and that is why these materials are commonly used for thermocouples. Moreover, $n$-type and $p$-type semiconductors have Seebeck coefficients with different signs; thus, if the two semiconductors composing a thermocouple have opposite doping, the contributions to the voltage reported in (1) are summed.

Energy scavengers exploiting the thermoelectrical effect consist of many thermocouples connected electrically in series and thermally in parallel to create a thermopile (Fig. 3). Additional elements, such as radiators and structures to convey the heat into 


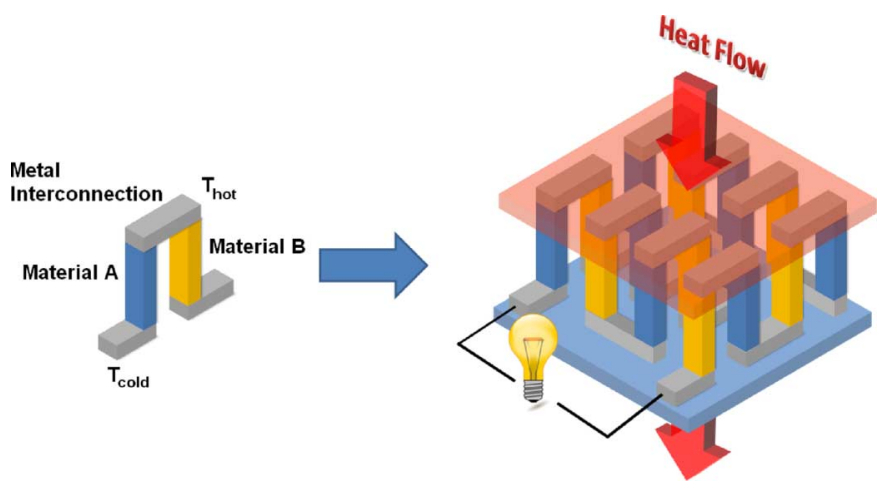

Fig. 3. Connection of many thermocouples (left) electrically in series and thermally in parallel forms a thermopile (right).

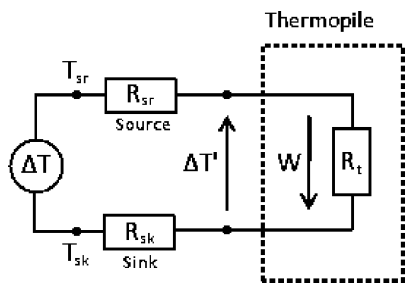

Fig. 4. Schematic example of a thermal circuit.

the thermopile legs, are normally used to increase the efficiency of these devices.

Thermopiles are usually inserted in a thermal circuit as depicted in Fig. 4. If we assume that the thermopile is placed between the human body (source) and the external ambient (sink), $R_{\mathrm{sr}}$ represents the thermal resistance during a heat exchange between the hot plate of the thermopile and the body, while $R_{\mathrm{sk}}$ represents the thermal resistance during the heat exchange between the cold plate of the thermopile and the ambient. The temperature difference between the body and the ambient is denoted as $\Delta T$, while $\Delta T^{\prime}$ is the temperature difference that is effectively present across the thermopile plates. The thermopile has a thermal resistance between the plates that is equal to $R_{\mathrm{t}}$, and a heat flux $W$ flows across it. In this description, the heat flux is considered constant: this assumption remains valid only for high values of thermal resistances $R_{\mathrm{sr}}$ and $R_{\mathrm{sk}}$.

The thermal resistance $R_{\mathrm{t}}$ of the thermopile is the parallel combination of the thermal resistance $R_{p}$ of the thermopile legs, also called pillars, and the thermal resistance $R_{\mathrm{a}}$ of the air in between the legs

$$
\left\{\begin{array}{l}
R_{p}=\frac{h}{2 n a^{2}} r_{p}, \\
R_{\mathrm{a}}=\frac{h}{A-2 n a^{2}} r_{\mathrm{a}}
\end{array}\right.
$$

where $A$ is the area of the thermopile plates; $h$ is the height of the pillars, equal to the distance between the plates; and $a$ is the lateral dimension of the pillars, assumed with the square base. The parameter $n$ represents the number of thermocouples (each one has two pillars) while $r_{\mathrm{a}}$ and $r_{p}$ are the thermal resistivity of the air and of the pillars, respectively.

It is possible to demonstrate that $R_{p}$ and $R_{\mathrm{a}}$ should be equal to maximize the generated power [20]. Thus, by equalizing the two previous expressions, the optimum number of thermocouples to be used in a thermopile is obtained

$$
n=\frac{r_{p}}{r_{p}+r_{\mathrm{a}}} \cdot \frac{A}{2 a^{2}}=\frac{r_{p}}{R_{\mathrm{a}}} \cdot \frac{h}{2 a^{2}} .
$$

The thermal gradient $\Delta T^{\prime}$ across the thermopile can be written as

$$
\Delta T^{\prime}=W R_{\mathrm{t}}=W \frac{R_{p}}{2}
$$

where the thermal resistance of the thermocouple $R_{\mathrm{t}}$ is the parallel of $R_{p}$ and $R_{\mathrm{a}}$. The thermal resistance $R_{p}$ has been fixed equal to $R_{\mathrm{a}}$ to maximize the generated power.

The electrical parameters of the thermopile can be determined as

$$
\left\{\begin{aligned}
\Delta V & =n S_{p} \Delta T^{\prime}=r_{p} \cdot \frac{S_{p} W}{4} \cdot \frac{h}{a^{2}}, \\
R & =2 n \rho \frac{h}{a^{2}}=\frac{r_{p}}{r_{p}+r_{\mathrm{a}}} \cdot \frac{\rho A}{h} \cdot\left(\frac{h}{a^{2}}\right)^{2} .
\end{aligned}\right.
$$

Equation (5a) returns the voltage drop across the entire thermopile and is obtained from (1) considering $S_{p}$ as the sum of the Seebeck coefficients of the two pillars of every thermocouple. Equation (5b) describes the electrical resistance $R$ of the thermopile, where $\rho$ is the electrical resistivity of the pillars.

Finally, the power delivered by the thermopile to a matched load is equal to

$$
P=\frac{\Delta V^{2}}{4 R}=\frac{1}{64} \frac{S_{p}^{2} W_{\mathrm{u}}^{2} A h}{\rho}\left(r_{p}+r_{\mathrm{a}}\right) r_{p}
$$

where $W_{\mathrm{u}}=W / A$ is the heat flux per unit area. A common figure of merit for the thermopiles is the following:

$$
\mathrm{ZT}=\frac{S_{p}^{2} r_{p}}{\rho} \Delta T^{\prime}
$$

where ZT is a dimensionless factor describing the performance of a thermocouple.

With the formulas just introduced, the voltage $V$ is shown to be proportional to $h / a^{2}$, while the power $P$ is proportional to $h$. The aspect $h / a$ between the height of the pillars and the lateral dimension is limited by technology aspects [21]. Thus, by increasing $h$ to obtain higher power, $h / a^{2}$ is decreased and, hence, the voltage. For this reason, there is no space for simultaneously optimizing power and voltage.

When low thermal gradients are applied, as in the case of human body applications, it is not straightforward to obtain voltage levels sufficient to power integrated circuitry. Commercial thermopiles commonly use bismuth telluride $\left(\mathrm{Bi}_{2} \mathrm{Te}_{3}\right)$, having a Seebeck coefficient $S= \pm 0.2 \mathrm{mV} /{ }^{\circ} \mathrm{C}$, due to the high ZT factor. By using that material for the thermocouple pillars, with a temperature difference $\Delta T^{\prime}=1^{\circ} \mathrm{C}, 5000$ thermocouples having a total area of about $25 \mathrm{~cm}^{2}$ are required to produce a voltage drop $\Delta V=1 \mathrm{~V}$ [22].

Moreover, a value of $\Delta T^{\prime}=1^{\circ} \mathrm{C}$ between the thermopile plates is not easily achieved. Based on results from [22], placing a commercial thermopile exploiting bismuth telluride 
TABLE I

HumAN TEMPERATURE GRADIENTS AT ROOM TEMPERATURE. TABLE FROM [23]

\begin{tabular}{|c|c|c|c|c|c|}
\hline Site & $\begin{array}{c}\text { Muscle } \\
\text { Thickness } \\
(\mathrm{mm})\end{array}$ & $\begin{array}{c}\text { Fat } \\
\text { Thickness } \\
(\mathrm{mm})\end{array}$ & $\begin{array}{c}\text { Rested } \\
(\mathrm{v}=0.2 \mathrm{~m} / \mathrm{s}) \\
\Delta T(\mathrm{~K})\end{array}$ & $\begin{array}{c}\text { Walking } \\
(\mathrm{v}=1.56 \mathrm{~m} / \mathrm{s}) \\
\Delta T(\mathrm{~K})\end{array}$ & $\begin{array}{c}\text { Running } \\
(\mathrm{v}=4.25 \mathrm{~m} / \mathrm{s}) \\
\Delta T(\mathrm{~K})\end{array}$ \\
\hline Abdomen & 16.34 & 14.8 & 1.73 & 3.8 & 4.75 \\
\hline Biceps & 34.6 & 3.33 & 0.45 & 1.22 & 1.7 \\
\hline Calf-posterior & 65.36 & 4.93 & 0.65 & 1.74 & 2.4 \\
\hline Chest & 33.45 & 7.26 & 0.94 & 2.37 & 3.18 \\
\hline Forearm & 26.04 & 3.24 & 0.44 & 1.16 & 1.63 \\
\hline Hamstring & 69.29 & 6.97 & 0.91 & 2.32 & 3.14 \\
\hline Lumbar & 37 & 6.54 & 0.85 & 2.18 & 2.96 \\
\hline Quadriceps & 54.54 & 6.42 & 0.82 & 2.12 & 2.89 \\
\hline Subscapular & 23.74 & 8.4 & 1.06 & 2.6 & 3.44 \\
\hline Suprapatellar & 29.42 & 6.23 & 0.81 & 2.08 & 2.81 \\
\hline Triceps & 41.84 & 5.92 & 0.78 & 2.02 & 2.75 \\
\hline
\end{tabular}

on a human forearm and considering an area $A=1 \mathrm{~cm}^{2}$, we can assume as reasonable the following values: $R_{\mathrm{sr}}=500 \mathrm{~K} / \mathrm{W}$, $R_{\mathrm{sk}}=1030 \mathrm{~K} / \mathrm{W}, R_{\mathrm{t}}=50 \mathrm{~K} / \mathrm{W}, T_{\mathrm{sr}}=37.5^{\circ} \mathrm{C}, T_{\mathrm{sk}}=28^{\circ} \mathrm{C}$. If the heat flux $W$ passing through the thermopile is

$$
W=\frac{\Delta T}{\left(R_{\mathrm{sr}}+R_{\mathrm{sk}}+R_{\mathrm{t}}\right)}
$$

a heat flux of about $W=6 \mathrm{~mW}$ flows through the area A. The product of the heat flux by the thermal resistance of the thermopile results in a temperature gradient $\Delta T^{\prime}=0.3^{\circ} \mathrm{C}$, instead of $1{ }^{\circ} \mathrm{C}$ previously assumed. With this value of $\Delta T^{\prime}$, the thermopile area must be increased up to $83 \mathrm{~cm}^{2}$ to obtain a voltage drop of $\Delta V=1 \mathrm{~V}$, making impractical any kind of implant application. In order to compare the different implantation areas, Table I shows calculated temperature gradients in different parts of the human body, with an ambient temperature of $25^{\circ} \mathrm{C}$.

Charge pumps are commonly used to elevate the voltage drops generated by the thermocouples, thus overcoming the problems related to the low voltages generated by the thermal scavengers [24]-[27]. Seiko proposed a thermoelectric wristwatch where a voltage of about $300 \mathrm{mV}$ is boosted until $1.5 \mathrm{~V}$, a useful level to power the $1-\mu \mathrm{W}$ quartz circuit [28]. The whole scavenger can provide a total power of $22.5 \mu \mathrm{W}$.

The literature offers some examples of thermopiles exploiting the human warmth and considerable effort has been invested to improve the technology performance of these systems. However, the power range of thermoelectric harvesters when exploiting the human warmth is still quite low and generally it does not exceed the few hundreds of microwatts when a thermal difference below $5 \mathrm{~K}$ is applied. In [29], $1.5 \mu \mathrm{W}$ with a $0.19 \mathrm{~cm}^{3}$ device exploiting a thermal gradient of $5 \mathrm{~K}$ is obtained. Similar results have been obtained by [30] with a device that is able to return $1 \mu \mathrm{W}$ with an area of $1 \mathrm{~cm}^{2}$ and a thermal gradient of $5 \mathrm{~K}$. ThermoLife [31] proposes a commercially available solution that is able to produce up to $30 \mu \mathrm{W}(10 \mu \mathrm{A}$ with a voltage drop of $3 \mathrm{~V}$ ) when a temperature difference of $5 \mathrm{~K}$ is applied. This device has a volume of $95 \mathrm{~mm}^{3}$ and a weight of $0.23 \mathrm{~g}$.

\section{Fuel Cells}

A fuel cell is an electrochemical device that generates current through the reaction of two chemical species flowing into it - the fuel on the anode site and the oxidant on the cathode site. The main difference between a fuel cell and a traditional battery

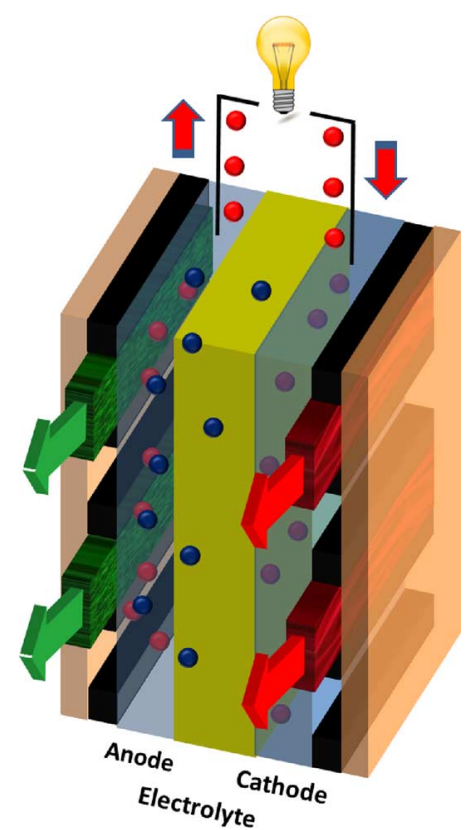

Fig. 5. Schematic description of a PEM fuel cell. Electrons cannot cross the membrane; thus, they have to follow a different path, generating current.

is that the former one can produce energy virtually without stopping, as long as the reactants continue to be present.

Fuel cells exist in many different kinds. The most common is the proton-exchange membrane (PEM) fuel cell (Fig. 5). The fuel and the oxidant streams are separated by a membrane that allows only protons produced on the anode site to cross it and to reduce the oxidant on the cathode site. The electrons generated on the anode cannot pass directly through the membrane to reach the cathode, consequently they have to follow a different external path, generating current.

Recently, a new kind of membrane-less fuel cell has been introduced [32], [33]. It exploits the laminar characteristics of microchannel flows to keep the two reactants separated, avoiding in this way the use of a membrane. Indeed, the PEM membrane needs constant humidification and it is subject to degradation and fuel crossover. In addition, the cost is usually quite high. Membrane-less fuel cells, instead, are more compact and enable significant miniaturization. Also, they do not require water management or a cooling system. A schematic example of a membrane-less fuel cell is reported in Fig. 6.

The use of fuel cells exploiting species present into the human body to harvest energy for implantable biosensors offers considerable advantages. The constant presence and availability of the reactants directly into the body makes unnecessary external recharging mechanisms or replacement. Implantable fuel cells that use glucose as a reactant are probably the most studied biofuel cells, due to the high availability of glucose in body fluids. Note that the investigation and development of these cells began in the 1960s [34].

Glucose fuel cells can be divided into two groups: 1) abiotically catalyzed and 2) enzymatically catalyzed. The former group utilizes nonbiological catalysts, such as noble metals or activated carbon. The latter group, instead, uses enzymes, such 


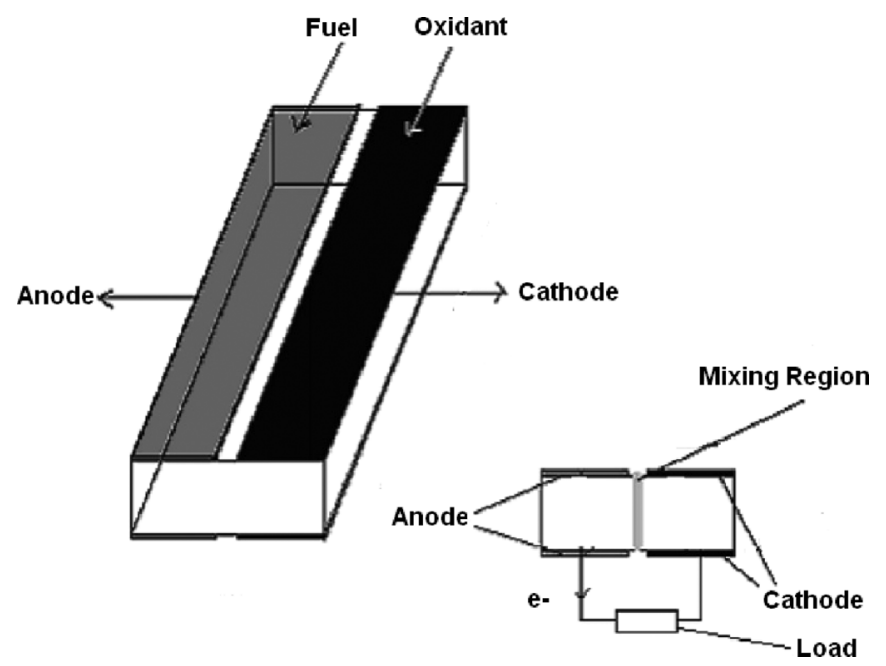

Fig. 6. Schematic description of a membrane-less fuel cell. The laminar characteristics of microchannel flows are used to keep reactants separated. Image elaborated from [40]

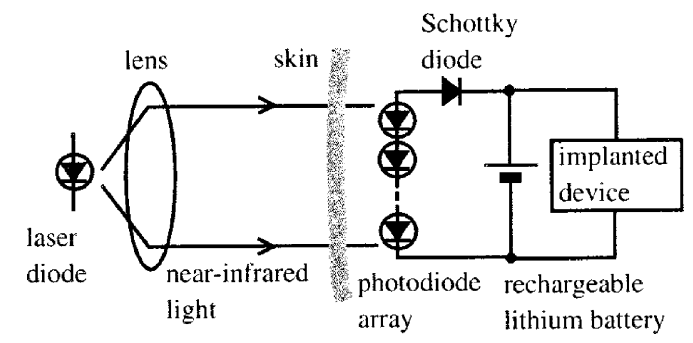

Fig. 7. Example of an IR harvester. The IR light emitted by an external source is caught by an implanted photodiode array. Image from [42].

as glucose oxidase or laccase, as catalysts to enable the electrode reactions. In [35], the state of the art of these devices is reported. During in vitro experiments, glucose fuel cells abiotically catalyzed can generate up to $50 \mu \mathrm{W} / \mathrm{cm}^{2}$ [36]. Experiments in vivo performed on a dog have generated $2.2 \mu \mathrm{W} / \mathrm{cm}^{2}$ over a period of 30 days [37]. Enzymatically catalyzed cells can provide a higher power density, up to $430 \mu \mathrm{W} / \mathrm{cm}^{2}$ [38]. Unfortunately, the lifetime of their enzymatic catalyst has not been proved beyond a period of one month [39].

\section{Infrared Radiation}

These kinds of harvesters exploit an external infrared (IR) source to transmit power to an implanted photodiode array; this array converts the received radiation into a current to properly charge the sensor battery (Fig. 7).

Some examples about this typology of scavenger are discussed in [41] and [42]. The device presented in [42] can supply power in the order of hundreds of microwatts up to a few milliwatts when illuminated by a power density of some milliwatts per square centimeter. The power returned by that photodiode array when enlightened by a power density of $22 \mathrm{~mW} / \mathrm{cm}^{2}$ for $17 \mathrm{~min}$ is sufficient to allow a $20-\mu \mathrm{A}$ cardiac pacemaker to operate for $24 \mathrm{~h}$. In terms of power, it means about $4 \mathrm{~mW}$ of transmitted power if the voltage of the pacemaker battery is considered to be equal to $2.4 \mathrm{~V}$, an average value between the nominal operating voltage $(2.8 \mathrm{~V})$ and the minimum operating voltage

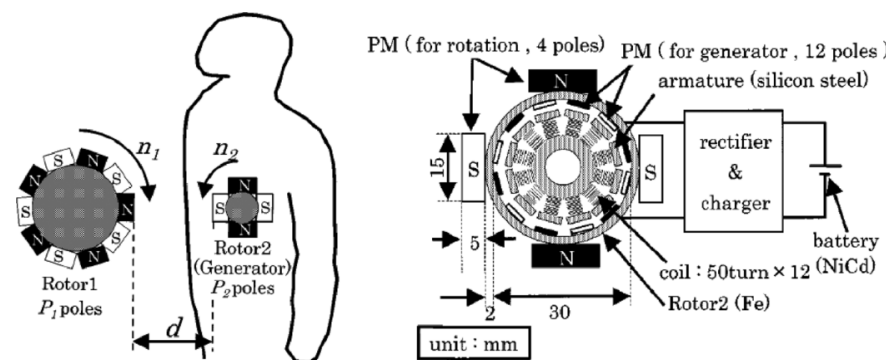

Fig. 8. Low-frequency magnetic fields are used to move an implanted rotor to generate power. Images elaborated from [44].

$(2.0 \mathrm{~V})$. This result has been obtained with a skin temperature rise of $1.4{ }^{\circ} \mathrm{C}$, a safe value for this kind of tissue [43].

This performance has been achieved by means of a large photodiode array, having an area of $2.1 \mathrm{~cm}^{2}$ and placed in a subcutaneous zone extremely close to the IR emitter $(0.8 \mathrm{~mm})$. To obtain the same performance without further temperature increase when a thicker tissue is used, the array dimensions can be enlarged. In [42], the same results are demonstrated where 2-mm human skin is used as barrier with a $10 \mathrm{~cm}^{2}$ photodiode array. Finally, increasing the emitter power densities to reduce the photodiode area is not recommended. Most of the heat generated by these scavengers is due to the array heating, and a smaller array receiving greater power density would involve a considerable temperature rise in the implantation zone.

Due to the area constraints and the difficulties of operating with tissues having high thickness, these kinds of harvesters are suitable for large devices not deeply implanted (i.e., cardiac pacemakers) but are practically ineffective with less invasive, deeply implanted devices.

\section{E. Low-Frequency Magnetic Fields}

This kind of harvester uses low-frequency magnetic fields placed outside the body to move an implanted magnetic rotor and to generate power exploiting its mechanical rotation (Fig. 8). Some solutions using this technique have been reported in the literature [44], [45].

One of the advantages in employing this kind of scavenger is the high quantity of power that can be delivered over a relatively long distance and even to deeply implanted biosensors. A maximum power of $3.1 \mathrm{~W}$ over a distance of $1.5 \mathrm{~cm}$ has been reported in [44], with an attractive force between the external and the internal rotors of $1.6 \mathrm{~N}$. This value has been obtained with a speed of the internal rotor of about $547 \mathrm{rad} / \mathrm{s}$. At a lower speed, up to $0.2 \mathrm{~W}$ can be delivered over a distance of $2 \mathrm{~cm}$ when the implanted rotor rotates at $273 \mathrm{rad} / \mathrm{s}$ and the resistance of the load is $200 \Omega$.

The major drawback of this technique is the large dimension of the implanted rotor, about $10 \mathrm{~cm}^{3}$. This volume hinders the implantation process. Moreover, moving components need to be periodically lubricated and substituted when worn out.

\section{F. Inductive Links}

The use of inductive links to power implanted sensors has been deeply investigated in the last decade. An inductive link consists of two coils. The primary coil is placed outside the 


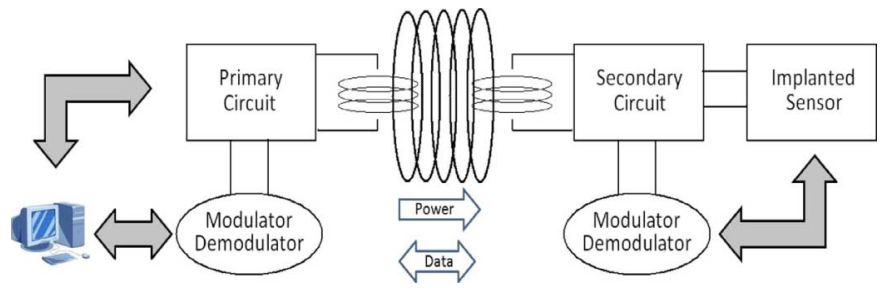

Fig. 9. Schematic representation of an inductive link performing bidirectional data transmission.

body, generating a variable magnetic field by means of an alternate current flowing in it. The change of the magnetic flux through the secondary coil generates an electromotive force across it, according to the Faraday-Neumann-Lenz law

$$
\varepsilon=-\frac{\mathrm{d} \phi_{\mathrm{B}}}{\mathrm{d} t}
$$

where $\varepsilon$ is the electromotive force generated by the change of the magnetic flux $\phi_{\mathrm{B}}$ through the secondary coil. The minus sign in the right side of the equation indicates that the generated electromotive force opposes the flux change. Using this method, power is transferred wirelessly through the body tissues, inducing an electromotive force in the implanted coil by means of an alternate current flowing on the external coil.

Inductive links present considerable additions, when compared with other kinds of power transmission previously discussed. Exploiting this technique, data can be transmitted from outside to inside the body (downlink) and vice-versa (uplink) without using a radio-frequency (RF) transmitter or receiver (Fig. 9). This can be feasible by modulating the load of the secondary coil, varying in this way the total load seen by the primary coil. This technique of data transmission, often called backscattering, enables saving a large amount of energy by avoiding the use of an implanted RF transmitter. Indeed, the RF transmitter usually has the highest power consumption among the components of an implantable biosensor. The capability of avoiding an implanted RF transmitter, together with a delivered power up to a few milliwatts, makes this technique particularly suitable for low-invasive implantable biosensors. Many applications involving inductive harvesting techniques have been reported in the literature. These solutions are discussed in detail in the following section, preceded by a brief theoretical introduction.

This technique presents strong analogies with the use of RFID passive tags [46]. An RFID passive tag consists of an integrated circuit (IC) with memory that is powered by the incidental field generated by a reader. Once powered, the chip generally transmits its identification tag to the reader by means of an RF transmitter or by exploiting the backscattering technique. Thus, an RFID passive tag needs energy only when the tag is required by the reader and it is not equipped with a battery. Implantable biosensors, instead, would need to be powered even when no reading occurs. Thus, in most cases, the biosensors must be equipped with an implanted battery.

In the market commercial products, exploiting inductive links to power fully implanted biosensors are available. One of these products is the neurostimulator "RestoreUltra" produced by Medtronic [47]. It is a stimulator of the spinal cord and is equipped with a battery that can be recharged from outside, avoiding invasive surgeries.

\section{G. Emerging Techniques}

The biological processes in animals and plants to collect, store, and reuse energy can inspire novel harvesting techniques. Some works have presented strong analogies between complex electronic systems and biological energy management [48].

For example, natural photosynthesis permits plants to collect energy by exploiting the solar light as source and $\mathrm{CO}_{2}$ and water as reactants. Several efforts have been invested to artificially reproduce the key step of the photosynthesis, in order to generate electrical power and energy fuels [49], [50]. In [51], a photosynthetic light conversion unit has been proposed that mimics the light-harvesting structure of phototrophic bacteria. An array of self-assembled bacteriochlorophyll aggregates captures and conveys the solar energy to an embedded "reaction center." This element has the role of energy acceptor and contributes to the charge transfer.

Another kind of scavenger inspired by the natural photosynthesis is the Gräetzel's cell or dye-sensitized solar cell (DSSC) [52]. This device has two electrodes, one of which is transparent to the solar light. In between the two electrodes, a molecular dye converts the solar light in electrons that reach the anode electrode by means of a stratum of titanium dioxide $\left(\mathrm{TiO}_{2}\right)$. The electron holes generated into the dye reach the cathode electrode through a liquid electrolyte. The whole mechanism is similar to the natural photosynthesis. Indeed, in this approach, the dye has the same role of the chlorophyll (conversion of light in electrons), the electrolyte has the same role of the water (replacement of the generated electrons), and the $\mathrm{TiO}_{2}$ has the same role of the $\mathrm{CO}_{2}$ (electrons acceptor).

This harvesting technique, although at the moment is not directly applicable to the field of the implantable biosensors, could be used in the near future to power devices not deeply implanted. A possible target, for example, could be subcutaneous biosensors due to their proximity to the skin and to the solar light.

\section{INDUCTIVE LINKS FOR REMOTE POWERING OF IMPLANTED BIOSENSORS}

\section{A. Introduction}

As mentioned before, inductive links are a well-suited solution for implanted biosensors due to the possibility of performing bidirectional communication between the internal sensor and the external control devices. Furthermore, their low dimension makes them compatible with low-invasive body implantations.

Almost all of the works reported in the literature utilize frequencies in the order of a few megahertz or lower [53]-[61]. The reason behind this choice is that this range of frequencies minimizes the power absorption by the tissues, yielding a higher transmission efficiency. At these frequencies, an inductive link can be analyzed by means of the Kirchhoff's laws using lumped parameters [62]. 


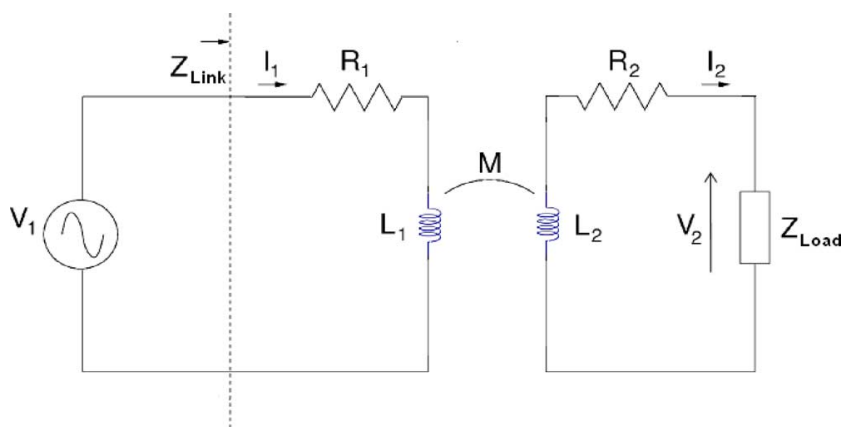

Fig. 10. Inductive link is obtained with a primary coil $\mathrm{L}_{1}$ connected to a power source and magnetically coupled to a secondary coil $\mathrm{L}_{2}$.

An example of an inductive link is illustrated in Fig. 10. The behavior of that circuit is described, according to (9), by the following formulas:

$$
\left\{\begin{array}{l}
V_{1}=+R_{1} I_{1}+\frac{\mathrm{d} \phi_{1}}{\mathrm{~d} t} \\
V_{2}=-R_{2} I_{2}-\frac{\mathrm{d} \phi_{2}}{\mathrm{~d} t}
\end{array}\right.
$$

where $R_{1}$ and $R_{2}$ represent the parasitic resistances of the two coils, $\phi_{1}$ is the total magnetic flux through the primary coil, and $\phi_{2}$ is the total magnetic flux through the secondary coil. The voltages and the currents reported in (10) are functions of time.

Defining the self-inductances $L_{1}$ and $L_{2}$ of the two coils and their mutual inductance $M$ as

$$
\left\{\begin{array}{l}
L_{1}=\frac{\partial \phi_{1}}{\partial I_{1}} \\
L_{2}=\frac{\partial \phi_{2}}{\partial I_{2}} \\
M=\frac{\partial \phi_{1}}{\partial I_{2}}=\frac{\partial \phi_{2}}{\partial I_{2}}
\end{array}\right.
$$

the expressions in (10) can be rewritten as

$$
\left\{\begin{array}{l}
V_{1}=+R_{1} I_{1}+L_{1} \frac{\mathrm{d} I_{1}}{\mathrm{~d} t}-M \frac{\mathrm{d} I_{2}}{\mathrm{~d} t} \\
V_{2}=-R_{2} I_{2}-L_{2} \frac{\mathrm{d} I_{2}}{\mathrm{~d} t}+M \frac{\mathrm{d} I_{1}}{\mathrm{~d} t} .
\end{array}\right.
$$

The system can be finally described in the frequency domain by

$$
\left\{\begin{array}{l}
V_{1}=+R_{1} I_{1}+j \omega L_{1} I_{1}-j \omega M I_{2} \\
V_{2}=-R_{2} I_{2}-j \omega L_{2} I_{2}+j \omega M I_{1}
\end{array}\right.
$$

where $V$ and $I$ represent now complex phasors.

It is now possible to define some important parameters of the inductive links. First of all, we can express the voltage across the load as a function of the source voltage

$$
V_{2}=\frac{j \omega M Z_{\text {load }}}{\omega^{2}\left(M^{2}-L_{1} L_{2}\right)+j \omega\left(L_{1} Z_{\text {load }}+L_{1} R_{2}+L_{2} R_{1}\right)+R_{1} Z_{\text {load }}+R_{1} R_{2}} V_{1} .
$$

Since the complex power of a sinusoidal source $V$ generating a current $I$ can be defined as $P=V I^{*} / 2$, the power transfer efficiency $\eta$ of the link can be written as

$$
\eta=\frac{\Re\left(V_{2} I_{2}^{*}\right)}{\Re\left(V_{1} I_{1}^{*}\right)}=\frac{\omega^{2} M^{2} R_{\text {load }}}{\omega^{2} M^{2}\left(R_{2}+R_{\text {load }}\right)+R_{1}\left[\left(R_{2}+R_{\text {load }}\right)^{2}+\left(\omega L_{2}+X_{\text {load }}\right)^{2}\right]}
$$

where $R_{\text {load }}$ and $X_{\text {load }}$ are the real and the imaginary parts of $Z_{\text {load }}$, respectively.

Finally, the input impedance seen by the voltage source $V_{1}$ can be expressed as

$$
Z_{l i n k}=R_{1}+j \omega L_{1}+\frac{\omega^{2} M^{2}}{R_{2}+j \omega L_{2}+Z_{l o a d}} .
$$

In most of the cases, the power signal driving the primary circuit is generated by a class-E amplifier, due to the higher efficiency of this circuit as compared to conventional class-B or class-C amplifiers [63].

Downlink transmission can be achieved by modulating the power signal generated by the class-E amplifier. Amplitudeshift keying (ASK) is one of the most preferred modulation techniques due to the simplicity of the demodulator that permits reducing the area and the power consumption of the implanted chip. In addition, this kind of modulation enables a simple synchronization between the transmitter and receiver. On the other hand, by modifying the amplitude of the power signal, the transmission efficiency becomes suboptimal. Furthermore, the data transmission rate is lower compared with other kinds of downlink modulations.

Another solution for the downlink communication is frequency-shift keying (FSK). It permits reaching a higher transmission rate when compared to the ASK, but this result is achieved by means of a more complex demodulator and by increasing the difficulty of synchronization between the transmitter and receiver [64].

Uplink transmission is commonly achieved by means of the load-shift keying (LSK). By modifying the impedance $Z_{\text {load }}$ of the secondary circuit, the load $Z_{\text {link }}$ seen by the primary circuit consequently varies, causing the current flowing on the primary coil to change. This change can be detected by an external demodulator, enabling uplink transmission without any internal RF transmitter.

\section{B. High-Frequency Inductive Links}

As previously mentioned, almost all the works reported in the literature utilize frequencies in the order of a few megahertz or lower [53]-[61] since this range of frequencies minimizes the power absorbed by the tissues, yielding a higher transmission efficiency. A recent work [65] has questioned this choice: the tissue absorption increases with the frequency only if the displacement current is omitted into the Maxwell equations (quasi-static assumption). In that case, the propagation of the electromagnetic field is governed by a diffusion equation and decays exponentially inside the tissues. The diffusion length in that case is inversely proportional to the square root of the frequency. This approximation is valid with good conductors, but is not valid if the human body is modeled as a low-loss dielectric. Without using the quasi-static assumption, thus performing a full-wave analysis, the penetration depth is shown to be asymptotically independent with the frequency, until dielectric dispersion occurs at very high frequency, in the microwave range [65]. For this reason, an optimum frequency in the gigahertz range is assumed. 


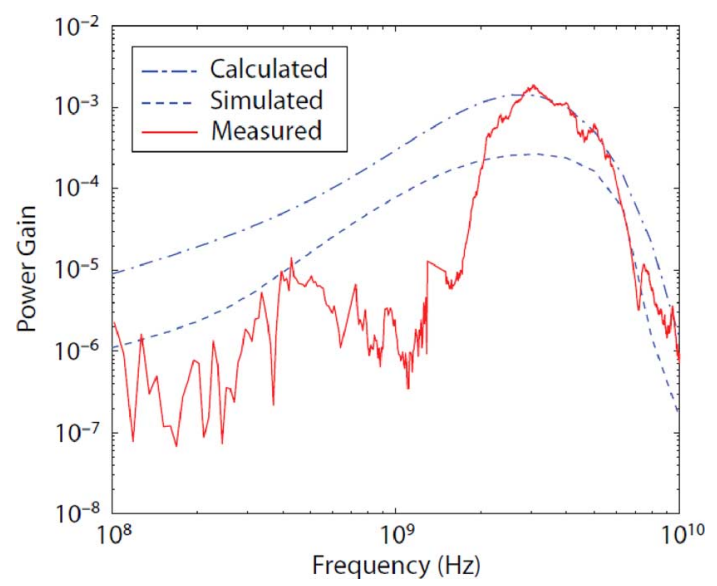

Fig. 11. Power gain obtained by [65] using an inductive link composed of two $4 \mathrm{~mm}^{2}$ coils. Simulations and measurements produce an optimal transmission frequency around $2.5 \mathrm{GHz}$.

In this range of frequencies, characterizing a network in terms of lumped elements, as we have done in the previous paragraph, is difficult and, in certain cases, intractable. In the microwave range, indeed, defining voltages and currents in a unique manner is not always possible. Moreover, the measurement of impedances and admittances, when possible, requires the use of short circuits or open circuits, not always easily realizable at high frequency. For these reasons, in the microwave and optical range, a description of the networks by means of scattering parameters is usually preferred [66].

A brief introduction of the scattering parameters theory is given in the Appendix. By means of the theoretical elements introduced there, [65] has simulated the performance of an inductive link consisting of two square coils with an area of $4 \mathrm{~mm}^{2}$. These coils are separated by a substrate of $1.5 \mathrm{~cm}$ (composed by air, $2 \mathrm{~mm}$ of skin, $1 \mathrm{~mm}$ of fat, $4 \mathrm{~mm}$ of muscle, $8 \mathrm{~mm}$ of skull and brain). The result obtained is reported in Fig. 11. The optimum frequency is located around $2.5 \mathrm{GHz}$, at least two orders of magnitude higher than the frequencies commonly used for the wireless power transmission. Moreover, this result has been validated by measurements using beef sirloin as substrate. The value of power gain is obtained by assuming simultaneous conjugate matching. The use of this range of frequencies would enable the realization of considerable smaller implantable coils, a higher data-transmission rate, and better tolerance to misalignments between coils.

Our simulations, using the same setup as in [65], have confirmed that result. The electrical parameters of the human tissues have been calculated using the 4-terms Cole-Cole relaxation model [67]. The tool used to perform the simulations is the Agilent Momentum.

Other works [68] have shown an increase of the power gain, together with a shift of the optimal frequency in the sub-gigahertz range, where the area of the external coil is increased up to $4 \mathrm{~cm}^{2}$. The optimum frequency is still two orders of magnitude higher than the frequencies commonly used. Our simulations, reported in Fig. 12, confirm that behavior where a $4 \mathrm{~cm}^{2}$ external coil is used. These coils are electrically large at very high

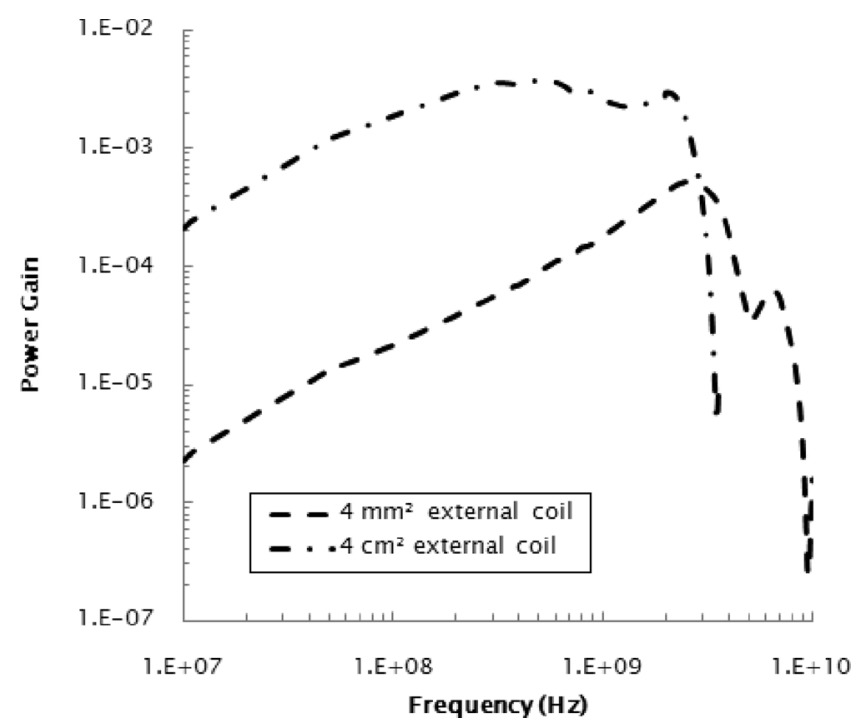

Fig. 12. With a bigger external coil $\left(4 \mathrm{~cm}^{2}\right)$, the power gain increases and the optimal frequency slightly shifts in the sub-gigahertz range.

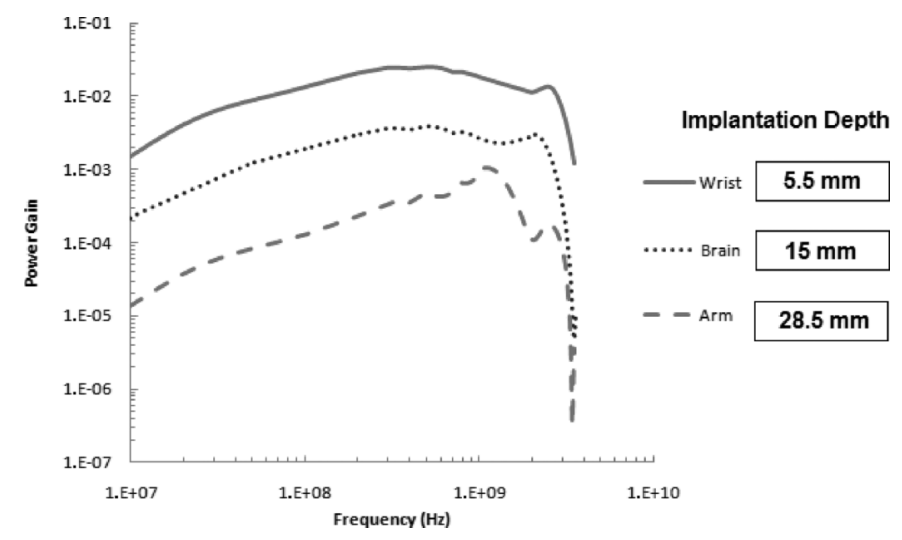

Fig. 13. Power gain obtained with a $4 \mathrm{~mm}^{2}$ receiving coil implanted in different parts of the body, where an external $4 \mathrm{~cm}^{2}$ transmitting coil is used. Power gain changes noticeably with the implantation depth, reported in the legend.

frequencies in the gigahertz range, thus resonance effects afflict the simulations with a sort of ripples in the high part of the simulation range.

Any kind of biomedical measurement performed by implanted devices requires careful analysis of the implantation site. Measurements of biochemical species normally present in the muscles of the limbs, such as the lactate, can be performed by devices implanted into the legs or the arms. Moreover, sensors dedicated to monitor the neural activity must be placed near the brain. Finally, devices implanted into the wrist can easily detect the heart rate. Thus, different implantation sites have been tested, maintaining constant the area of the external coil at $4 \mathrm{~cm}^{2}$. The individuation of the sites and the definition of their geometries have been possible thanks to the Visible Human Project, implementing 3-D real-time navigation into the human body [69]. The results of these simulations are reported in Fig. 13. The optimum frequency still remains in the sub-gigahertz range, while the absolute value of the power gain noticeably changes with the implantation depth. 
TABLE II

IMPLANTABLE DEVICES EXPLOITING INDUCTIVE LINKS FOR WIRELESS POWER TRANSMISSION

\begin{tabular}{|c|c|c|c|c|c|c|c|c|c|c|}
\hline Ref. & $\begin{array}{c}\text { Coil Area } \\
\left(\lambda=10 \mathrm{~mm}^{2}\right)\end{array}$ & $\begin{array}{l}\text { Coil Thickness } \\
(\sigma=1 \mathrm{~mm})\end{array}$ & $\begin{array}{c}\text { Carrier } \\
\text { Frequency }\end{array}$ & $\begin{array}{c}\text { Data } \\
\text { Transmission }\end{array}$ & Bit Rate & $\begin{array}{c}\text { Power } \\
\text { Consumption }\end{array}$ & Efficiency & Distance & $\begin{array}{c}\text { Measurement } \\
\text { Site }\end{array}$ & $\begin{array}{c}\text { Target } \\
\text { Site }\end{array}$ \\
\hline [53] & $\begin{array}{l}\text { Tx: } 7.8 \lambda \\
\text { Rx: } 1.7 \lambda\end{array}$ & $\begin{array}{l}\text { Tx: } 2 \sigma \\
\text { Rx: } 2.5 \sigma\end{array}$ & $4 \mathrm{MHz}$ & $\begin{array}{l}\text { Downlink: PWM-ASK } \\
\text { Uplink: LSK }\end{array}$ & Uplink: 125 kbps & $90 \mathrm{~mW}^{(a)}$ & & $5 \mathrm{~mm}$ & Air & $\begin{array}{c}\text { Neural Recording } \\
\text { System }\end{array}$ \\
\hline [54] & $\begin{array}{l}\text { Tx: } 196 \lambda \\
\text { Rx: } 31.4 \lambda\end{array}$ & $\begin{array}{l}\text { Tx: } 9.5 \sigma \\
\text { Rx: } 5 \sigma\end{array}$ & $4 \mathrm{MHz}$ & Uplink: LSK & Uplink: $5 \div 10 \mathrm{kbps}$ & $11 \mathrm{~mW}^{(b)}$ & & $28 \mathrm{~mm}$ & $\begin{array}{c}\text { Water Bearing } \\
\text { Colloids }\end{array}$ & \\
\hline [55] & $\begin{array}{l}\text { Tx: } 13200 \lambda \\
\text { Rx: } 7.9 \lambda\end{array}$ & $\begin{array}{l}\text { Tx: } 300 \sigma \\
\text { Rx: } 13 \sigma\end{array}$ & $1 \mathrm{MHz}$ & & & $150 \mathrm{~mW}^{(b)}$ & $1 \%(\min )$. & $205 \mathrm{~mm}$ & PVC Barrel & Stomach \\
\hline [56] & Rx: $10 \lambda$ & $\mathrm{Rx}: 0.035 \sigma$ & $1 \mathrm{MHz}$ & & & $10 \mathrm{~mW}^{(b)}$ & $18.9 \%$ (max.) & $5 \mathrm{~mm}$ & Air & $\begin{array}{l}\text { Cerebral } \\
\text { Cortex }\end{array}$ \\
\hline [57] & $\begin{array}{r}\text { Tx: } 283 \lambda \\
\text { Rx: } 31.4 \lambda \\
\end{array}$ & & $0.7 \mathrm{MHz}$ & $\begin{array}{l}\text { Downlink: ASK } \\
\text { Uplink: LSK }\end{array}$ & $\begin{array}{c}\text { Downlink: } 60 \mathrm{kbps} \\
\text { Uplink: } 60 \mathrm{kbps}\end{array}$ & $50 \mathrm{~mW}^{(b)}$ & $36 \%$ (max.) & $30 \mathrm{~mm}$ & & \\
\hline [58] & $\begin{array}{l}\text { Tx: } 31.4 \lambda \\
\text { Rx: } 7.9 \lambda\end{array}$ & & $10 \mathrm{MHz}$ & $\begin{array}{l}\text { Downlink: ASK } \\
\text { Uplink: BPSK }\end{array}$ & $\begin{array}{l}\text { Downlink: } 120 \text { kbps } \\
\text { Uplink: } 234 \text { kbps }\end{array}$ & $\begin{array}{l}\approx 22.5 \mathrm{~mW} \text { in vitro }(b) \\
\approx 19 \mathrm{~mW} \text { in vivo }(b)\end{array}$ & & $15 \mathrm{~mm}$ & Rabbit & Muscle \\
\hline [59] & $\begin{array}{l}\text { Tx: } 196.3 \lambda \\
\text { Rx: } 3.5 \lambda\end{array}$ & $\begin{array}{l}\text { Tx: } 5 \sigma \\
\text { Rx: } 1.9 \sigma\end{array}$ & $5 \mathrm{MHz}$ & Downlink: OOK & Downlink: 100 kbps & $\approx 5 \div 10 \mathrm{~mW}^{(a)}$ & & $40 \mathrm{~mm}$ & & $\begin{array}{c}\text { Neural } \\
\text { Stimulator }\end{array}$ \\
\hline [60] & $\mathrm{Rx}: 112.5 \lambda$ & $\mathrm{Rx}: 10 \sigma$ & $6.78 \mathrm{MHz}$ & $\begin{array}{l}\text { Downlink: OOK } \\
\text { Uplink: LSK }\end{array}$ & Uplink: $200 \mathrm{kbps}$ & $120 \mathrm{~mW}^{(a)}$ & $20 \%(\min )$ & $25 \mathrm{~mm}$ & $\begin{array}{c}\text { Dog } \\
\text { Shoulder }\end{array}$ & $\begin{array}{l}\text { Muscular } \\
\text { Stimulator }\end{array}$ \\
\hline [61] & $\begin{array}{l}\text { Tx: } 152 \lambda \\
\text { Rx: } 3.2 \lambda\end{array}$ & $\mathrm{Rx}: 1 \sigma$ & $13.56 \mathrm{MHz}$ & Uplink: LSK & & $0.198 \mathrm{~mW}^{(b)}$ & & $40 \mathrm{~mm}$ & & $\begin{array}{l}\text { Subcutaneous } \\
\text { Tissue }\end{array}$ \\
\hline [70] & $\begin{array}{l}\text { Tx: } 40 \lambda \\
\text { Rx: } 0.4 \lambda\end{array}$ & $\begin{array}{l}\text { Tx: } 0.038 \sigma \\
\text { Rx: } 0.038 \sigma\end{array}$ & $915 \mathrm{MHz}$ & & & $0.14 \mathrm{~mW}^{(b)}$ & $0.06 \%(\max )$ & $15 \mathrm{~mm}$ & $\begin{array}{l}\text { Bovine } \\
\text { Muscle }\end{array}$ & \\
\hline
\end{tabular}

(a) Power consumed by the implantable sensor.

(b) Power effectively supplied by the inductive link.

To conclude the section dedicated to the high-frequency inductive links, we report an example of an implantable chip, exploiting high-frequency power transmission [70]. The working frequency is $915 \mathrm{MHz}$ and it can deliver a maximum power of $140 \mu \mathrm{W}$ at $1.2 \mathrm{~V}$, sending $0.25 \mathrm{~W}$ through $15 \mathrm{~mm}$ of tissue. The implanted coil has an area of $4 \mathrm{~mm}^{2}$, while the transmitting coil has an area of $4 \mathrm{~cm}^{2}$.

\section{Specific Absorption Rate}

An important parameter to be considered, when the power source is close to the body, is the specific absorption rate (SAR) of the tissues

$$
\mathrm{SAR}=\frac{\sigma|\mathbf{E}|^{2}}{\rho}
$$

where $\sigma$ and $\rho$ are the conductivity and the density of the involved tissues, respectively, and $|\mathbf{E}|^{2}$ is the norm of the incident electric field. The SAR value, measured in watts per kilogram, determines the quantity of power absorbed by the tissues and is strictly related to their temperature increase. The SAR is usually calculated as an average over a region of $1 \mathrm{~g}$ or $10 \mathrm{~g}$ of tissue, depending on the national laws.

In the IEEE guideline [71], the SAR limits for a general public exposure are $4 \mathrm{~W} / \mathrm{kg}$ for any $10 \mathrm{~g}$ of tissue of hands, wrists, feet, and ankles; $1.6 \mathrm{~W} / \mathrm{kg}$ for any $1 \mathrm{~g}$ of any other tissue. In the ICNIRP guideline [72], the SAR limits for a general public exposure are $2 \mathrm{~W} / \mathrm{kg}$ for any $10 \mathrm{~g}$ of head and trunk and $4 \mathrm{~W} / \mathrm{kg}$ for any $10 \mathrm{~g}$ of the limbs.

In [73], a large number of cases where people were daily subjected to microwave fields with densities in the order of a few milliwatts per square centimeter have been analyzed, without finding any significant health implication. In addition, it reports the trend of SAR on humans with respect to the frequency, when an incident field of $1 \mathrm{~mW} / \mathrm{cm}^{2}$ is applied. The maximum absorption is around $70 \mathrm{MHz}$, where SAR is equal to $0.225 \mathrm{~W} / \mathrm{kg}$. At higher frequencies, around $2.45 \mathrm{GHz}$, SAR is one order of magnitude smaller, being equal to $0.028 \mathrm{~W} / \mathrm{kg}$. This value is comparable with that obtained around $20 \mathrm{MHz}$, where SAR is equal to $0.015 \mathrm{~W} / \mathrm{kg}$.
Recent studies have focused on the neurological effects of microwaves. The head has become the primary focus due to the wide use of electronic devices for mobile communication. With certain kinds of mobile phones, a maximum SAR of $3.72 \mathrm{~W} / \mathrm{kg}$, averaged over $1 \mathrm{~g}$ of tissues of the head, can be reached at $900 \mathrm{MHz}$ while the mobile phone is transmitting $600 \mathrm{~mW}$ [74]. If averaged over $10 \mathrm{~g}$ of tissues, the SAR can be $1.99 \mathrm{~W} / \mathrm{kg}$. The increase of temperature of the head tissues is included in the range between 0.22 and $0.43^{\circ} \mathrm{C}$. These measurements have been performed with a radiated power of $600 \mathrm{~mW}$. Reference [75] found no positive evidence of risk to the health or the brain related to pulsed or continuous exposure to microwave having power levels typical of Global System for Mobile Communications (GSM) communication, such as the ones previously reported.

\section{Comparison of the Solutions}

To recap, in Table II, a summary of some works that exploit inductive links to power implantable devices is reported. For each of these, some of the key parameters have been extracted and reported in the table, to enable fast comparison.

In contrast to other harvesting techniques presented before, inductive links are able to deliver a noticeable amount of power (order of milliwatts) while occupying a relatively small area. Furthermore, power can be transferred wirelessly through the body tissues without any physical link that could cause infections or discomfort.

The distance between the coils is in the order of millimeters, ranging from 5 to $205 \mathrm{~mm}$. Most of the works presented in Table II perform data communication between the external devices and the implanted sensors, with data rates up to few hundreds kilobits per second. Finally, all of the works reported in Table II use frequencies in the order of a few megahertz with the exception of the last one, where a frequency in the gigahertz range is used. The amount of power delivered by this last solution and its efficiency are noticeably smaller than the others, but they have been obtained using the smallest implanted coil among the others. Moreover, the use of a high-frequency carrier 
TABLE III

Comparison Between the Different HaRvesting Techniques

\begin{tabular}{|c|c|c|c|c|}
\hline Technique & Ref. & $\begin{array}{l}\text { Returned } \\
\text { Power }\end{array}$ & Advantages & Drawbacks \\
\hline \multirow{5}{*}{ Kinetic } & [13] & $\simeq 44 \mu \mathrm{W}$ & & Large dimension $\left(\simeq 7 \mathrm{~cm}^{2}\right)$. \\
\hline & {$[14]$} & $58 \mu \mathrm{W}$ & & \\
\hline & {$[15]$} & $80 \mu \mathrm{W}$ & Non resonant. & \\
\hline & {$[16]$} & $60 \mu \mathrm{W}$ & Dimension $\left(\leq 1 \mathrm{~cm}^{2}\right)$ & Performance can decrease when packaged. \\
\hline & {$[17]$} & $40 \mu \mathrm{W}$ & & \\
\hline \multirow{4}{*}{ Thermoelectric } & [28] & $22.5 \mu \mathrm{W}$ & & Low voltage drop. \\
\hline & [29] & $1.5 \mu \mathrm{W}$ & & \\
\hline & {$[30]$} & $1 \mu \mathrm{W}$ & & \\
\hline & [31] & $30 \mu \mathrm{W}$ & & \\
\hline \multirow{3}{*}{ Fuel Cells } & [36] & $50 \mu \mathrm{W} / \mathrm{cm}^{2}$ & & In vitro. \\
\hline & [37] & $2.2 \mu \mathrm{W} / \mathrm{cm}^{2}$ & In vivo. & \\
\hline & [38] & $430 \mu \mathrm{W} / \mathrm{cm}^{2}$ & High power density. & Short lifetime. \\
\hline Infrared Radiation & [42] & $\simeq 4 \mathrm{~mW}$ & High power. & $\begin{array}{l}\text { Dimension increases when thick tissues } \\
\text { are used }\left(10 \mathrm{~cm}^{2} \text { for } 2 \mathrm{~mm} \text { of human skin). }\right.\end{array}$ \\
\hline $\begin{array}{l}\text { Low Frequency } \\
\text { Magnetic Field }\end{array}$ & [44] & up to $3.1 \mathrm{~W}$ & $\begin{array}{c}\text { Extremely high power } \\
\text { over a big distance (up to } 2 \mathrm{~cm} \text { ). }\end{array}$ & $\begin{array}{l}\text { Extremely big dimension }\left(10 \mathrm{~cm}^{3}\right) \text {. } \\
\text { Moving parts need to be lubricated and substituted when worn out. }\end{array}$ \\
\hline \multirow{6}{*}{ Inductive Links } & {$[54]$} & $11 \mathrm{~mW}$ & \multirow{5}{*}{$\begin{array}{l}\text { High quantity of power. } \\
\text { Data transmission } \\
\text { (except }[55,56]) .\end{array}$} & \\
\hline & [55] & $150 \mathrm{~mW}$ & & \\
\hline & {$[56]$} & $10 \mathrm{~mW}$ & & \\
\hline & [57] & $50 \mathrm{~mW}$ & & \\
\hline & {$[58]$} & up to $22.5 \mathrm{~mW}$ & & \\
\hline & [70] & $0.14 \mathrm{~mW}$ & $\begin{array}{l}\text { Extremely small dimension. } \\
\text { Possibility of high data rate. }\end{array}$ & $\begin{array}{c}\text { Extremely low efficiency. } \\
\text { High transmitted power }(0.25 \mathrm{~W}) \text {. }\end{array}$ \\
\hline
\end{tabular}

could allow a higher data rate between the external devices and the implanted sensors.

\section{CONCLUSiOn}

The field of implantable biosensors is attracting increasing interest by offering wide applications for the future medicine. In this paper, we have analyzed some of the most popular techniques used for the design of implantable biosensors to harvest energy from the ambient and to remotely transmit it. For each technique, we have listed the advantages and the possible drawbacks. A special emphasis has been placed on the inductive links that are able to deliver power wirelessly through the tissues and to perform bidirectional data communication with the implanted devices. In addition, high-frequency inductive links have been considered, showing the solutions presented in the literature and reporting the results returned by the simulations.

To summarize, in Table III, different solutions cited in the paper have been listed to enable fast comparison among the different techniques described. For each example, the returned power, the advantages, and the drawbacks are listed. With the examples reported in this table, inductive links seem to deliver the highest power levels. Moreover, the absence of moving parts, together with the possibility of achieving bidirectional data communication without an implanted RF transmitter, makes these techniques particularly suitable for power-implanted devices.

High-frequency inductive links can achieve higher data rates and exhibit better tolerance to misalignments compared to the low-frequency solutions. Moreover, they support realizing implantable coils with an extremely low form factor compared to other solutions exploiting inductive powering. The efficiency reached by this approach is, however, still lower than that obtained by classical approaches operating in the megahertz range.

\section{APPENDIX}

We append here a brief introduction to the theory of scattering parameters. As introduced in Section III, at high frequencies, such as in the microwave range, it can be difficult or even impossible to describe a circuit by using voltages and currents. Moreover, the measurement of impedances and admittances may require the use of short circuits or open circuits that are not always easy to realize at high frequency. Consequently, in the microwave and optical range, a description of the networks by means of scattering parameters is usually preferred [66].

Referring to Fig. 14, each voltage and current of a two-port network can be divided into two components: one incident and the other reflected

$$
\left\{\begin{array}{l}
V_{n}=V_{n}^{+}+V_{n}^{-} \\
I_{n}=\frac{1}{Z_{0 n}}\left(V_{n}^{+}-V_{n}^{-}\right)
\end{array}\right.
$$

where $V_{n}^{+}$and $V_{n}^{-}$are the incident and the reflected components, respectively, and $Z_{0 n}$ is the characteristic impedance of port $n$. Both voltages and currents are represented as complex vectors. 


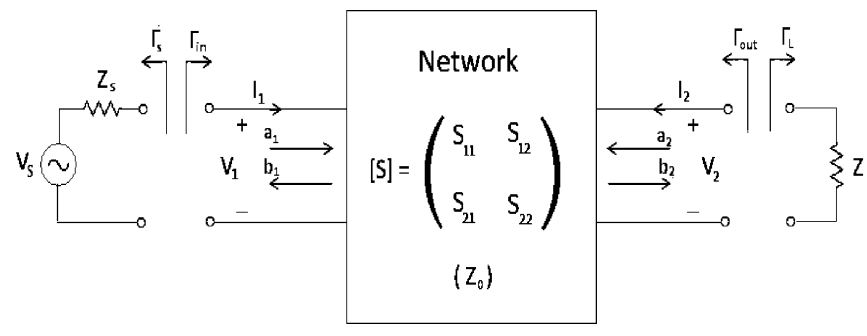

Fig. 14. Schematic description of a two-ports network by means of the scattering parameters.

When the various ports of a network present different characteristic impedances, it has the sense to normalize the components just introduced

$$
\left\{\begin{array}{l}
a_{n}=\frac{1}{\sqrt{Z_{0 n}}} V_{n}^{+} \\
b_{n}=\frac{1}{\sqrt{Z_{0 n}}} V_{n}^{-} .
\end{array}\right.
$$

Thus, it is possible to rewrite the voltages and the currents of the network as

$$
\left\{\begin{array}{l}
V_{n}=\sqrt{Z_{0 n}}\left(a_{n}+b_{n}\right) \\
I_{n}=\frac{1}{\sqrt{Z_{0 n}}}\left(a_{n}-b_{n}\right)
\end{array}\right.
$$

where $n$ is still referred to the port. It is now possible to introduce the generalized scattering matrix $\mathrm{S}$

$$
\left\{\begin{array}{l}
b_{1}=S_{11} a_{1}+S_{12} a_{2} \\
b_{2}=S_{21} a_{1}+S_{22} a_{2}
\end{array}\right.
$$

where the generic element $S_{i j}$ can be expressed as

$$
S_{i j}=\left.\frac{b_{\mathrm{i}}}{a_{j}}\right|_{\mathrm{a}_{k}=0 \text { for } k \neq j} .
$$

In most of the practical situations, the characteristic impedance is the same for all ports of a network. In that case, its value is indicated as $Z_{0}$ and is called the characteristic impedance of the network. Consequently, the normalization factor will be the same for all the ports and is equal to $\sqrt{Z_{0}}$.

The use of a normalization factor involves some advantages. First, different from $V_{n}$ and $I_{n}$, the normalized factors $a_{n}$ and $b_{n}$ are directly related to the power flow, with $\left|a_{n}\right|^{2}$ and $\left|b_{n}\right|^{2}$ being the power incident and reflected at port $n$.

The coefficients indicated with the greek letter $\Gamma$ in Fig. 14 are called reflection coefficients and describe the ratio of the amplitude of the reflected wave to the amplitude of the incident wave. In relation to Fig. 14, these coefficients can be written as

$$
\left\{\begin{array}{l}
\Gamma_{\mathrm{S}}=\frac{Z_{\mathrm{S}}-Z_{0}}{Z_{\mathrm{S}}+Z_{0}} \\
\Gamma_{\mathrm{L}}=\frac{Z_{\mathrm{L}}-Z_{0}}{Z_{\mathrm{L}}+Z_{0}}
\end{array}\right.
$$

where $Z_{\mathrm{S}}$ and $Z_{\mathrm{L}}$ are the source and load impedances, respectively.

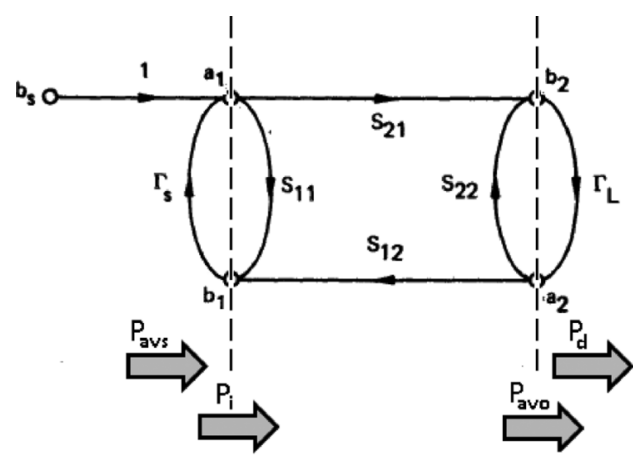

Fig. 15. Signal flowchart of a two-ports network

The signals involved in the two-ports network reported in Fig. 14 can be expressed by means of a signal flow graph, as that shown in Fig. 15. The incident wave generated by the source $V_{\mathrm{S}}$ is indicated as $b_{\mathrm{S}}$ and it can be shown that $b_{\mathrm{S}}=V_{\mathrm{S}} \sqrt{Z_{0}} /\left(Z_{\mathrm{S}}+Z_{0}\right)$.

Referring to Fig. 15, it is now possible to introduce the definitions of power gain

$$
\left\{\begin{aligned}
G_{\mathrm{T}} & \doteq \frac{P_{\mathrm{d}}}{P_{\mathrm{avs}}}, & & \text { Transducer Power Gain } \\
G & \doteq \frac{P_{\mathrm{d}}}{P_{\mathrm{i}}}, & & \text { Power Gain } \\
G_{\mathrm{A}} & \doteq \frac{P_{\mathrm{avo}}}{P_{\mathrm{avs}}}, & & \text { Available Gain }
\end{aligned}\right.
$$

where $P_{\text {avs }}$ is the power available from the source, $P_{\mathrm{i}}$ is the power at the input port of the network, $P_{\text {avo }}$ is the power available at the output port of the network, and $P_{\mathrm{d}}$ is power delivered to the load. The different power gains can be rewritten as

$$
\left\{\begin{aligned}
G_{\mathrm{T}} & =\frac{1-\left|\Gamma_{\mathrm{S}}\right|^{2}}{\left|1-\Gamma_{\mathrm{in}} \Gamma_{\mathrm{S}}\right|^{2}} \cdot\left|S_{21}\right|^{2} \cdot \frac{1-\left|\Gamma_{\mathrm{L}}\right|^{2}}{\left|1-S_{22} \Gamma_{\mathrm{L}}\right|^{2}} \\
G & =\frac{1}{1-\left|\Gamma_{\mathrm{in}}\right|^{2}} \cdot\left|S_{21}\right|^{2} \cdot \frac{1-\left|\Gamma_{\mathrm{L}}\right|^{2}}{\left|1-S_{22} \Gamma_{\mathrm{L}}\right|^{2}} \\
G_{\mathrm{A}} & =\frac{1-\left|\Gamma_{\mathrm{S}}\right|^{2}}{\left|1-S_{11} \Gamma_{\mathrm{S}}\right|^{2}} \cdot\left|S_{21}\right|^{2} \cdot \frac{1}{1-\left|\Gamma_{\text {out }}\right|^{2}}
\end{aligned}\right.
$$

where $\Gamma_{\text {in }}=S_{11}+S_{12} S_{21} \Gamma_{\mathrm{L}} /\left(1-S_{22} \Gamma_{\mathrm{L}}\right)$ and $\Gamma_{\text {out }}=S_{22}+$ $S_{12} S_{21} \Gamma_{\mathrm{S}} /\left(1-S_{11} \Gamma_{\mathrm{S}}\right)$.

An important situation is when the input impedance and the output impedance of the network are conjugately matched to the source impedance and to the load impedance, respectively. In this case, named simultaneous conjugate match, the three definitions of power gain that we have reported assume the same maximum value.

Finally, it is useful to introduce the voltage gain at the ports of the network. By defining

$$
\left\{\begin{array}{l}
A_{11} \doteq \Gamma_{\mathrm{S}} S_{11}-1 \\
A_{12} \doteq \Gamma_{\mathrm{S}} S_{12} \\
A_{21} \doteq \Gamma_{\mathrm{L}} S_{21} \\
A_{22} \doteq \Gamma_{\mathrm{L}} S_{22}-1
\end{array}\right.
$$


the voltage gain is equal to

$$
A_{\mathrm{v}}=\frac{a_{2}+b_{2}}{a_{1}+b_{1}}=\frac{-A_{21}+\left(A_{22} S_{21}-S_{22} A_{21}\right)}{A_{22}+\left(A_{22} S_{11}-S_{12} A_{21}\right)} .
$$

With these theoretical elements, a two-port network, such as an inductive link for remote powering, can be analyzed by the means of the scattering parameters. As previously mentioned, the description of a network by means of scattering parameters is always possible, while it is not always possible or convenient to use an approach exploiting lumped elements.

\section{ACKNOWLEDGMENT}

The first author would like to thank J. Anders from EPFL and A. A. M. Perez from Agilent Technologies for the precious suggestions and the useful discussions about microwave networks and scattering parameters, as well as K. M. Silay and Dr. C. Dehollain from EPFL for advice on inductive links and their practical realization.

\section{REFERENCES}

[1] G. Buzsaki, "Large-scale recording of neuronal ensembles," Nature Neurosci., vol. 7, no. 5, pp. 446-451, May 2004.

[2] M. Nicolelis, D. Dimitrov, J. Carmena, R. Crist, G. Lehew, J. Kralik, and S. Wise, "Chronic, multisite, multielectrode recordings in macaque monkeys," in Proc. Nat. Acad. Sci. United States Amer., 2003, vol. 100, pp. $11041-11046$.

[3] Z. Zumsteg, C. Kemere, S. O'Driscoll, G. Santhanam, R. Ahmed, K. Shenoy, and T. Meng, "Power feasibility of implantable digital spikesorting circuits for neural prosthetic systems," IEEE Trans. Neural Syst. Rehab. Eng., vol. 13, no. 3, pp. 272-279, Sep. 2005.

[4] K. Wise, D. Anderson, J. Hetke, D. Kipke, and K. Najafi, "Wireless implantable microsystems: High-density electronic interfaces to the nervous systems," Proc. IEEE, vol. 92, no. 1, pp. 76-97, Jan. 2004.

[5] M. Carrozza, G. Cappiello, S. Micera, B. Edin, L. Beccai, and C. Cipriani, "Design of a cybernetic hand for perception and action," Biol. Cybern., vol. 95, no. 6, pp. 629-644, Dec. 2006.

[6] M. C. Frost and M. E. Meyerhoff, "Implantable chemical sensors for real-time clinical monitoring: Progress and challenges," Current Opin. Chem. Biol., vol. 6, no. 5, pp. 633-641, 2002.

[7] G. Lazzi, "Thermal effects of bioimplants," IEEE Eng. Med. Biol. Mag., vol. 24, no. 5, pp. 75-81, Sep./Oct. 2005.

[8] A. Du Pasquier, I. Plitz, S. Menocal, and G. Amatucci, "A comparative study of li-ion battery, supercapacitor and nonaqueous asymmetric hybrid devices for automotive applications," J. Power Sources, vol. 115, no. 1, pp. 171-178, Mar. 2003.

[9] Fraunhofer Inst. Microelectron. Circuits Syst., Integrated pressure sensors for medical use. [Online]. Available: http://www.ims.fraunhofer.de/

[10] P. Mitcheson, E. Yeatman, G. Rao, A. Holmes, and T. Green, "Energy harvesting from human and machine motion for wireless electronic devices," Proc. IEEE, vol. 96, no. 9, pp. 1457-1486, Sep. 2008.

[11] M. Hayakawa, "Electronic wristwatch with generator," U.S. Patent 5 $001685,1989$.

[12] M. Hayakawa, "A study of the new energy system for quartz watches (ii) - The effective circuit for the system," in Congr. Eur. Chronométrie, 1988.

[13] H. Goto, T. Sugiura, Y. Harada, and T. Kazui, "Feasibility of using the automatic generating system for quartz watches as a leadless pacemaker power source," Med. Biol. Eng. Comput., vol. 37, no. 1, pp. 377-380, Jan. 1999.

[14] R. Tashiro, N. Kabei, K. Katayama, Y. Ishizuka, F. Tsuboi, and K. Tsuchiya, "Development of an electrostatic generator that harnesses the motion of a living body," Int. J. Jpn. Soc. Mechan. Eng., vol. 43, pp. 916-922, 2000.
[15] P. Miao, P. Mitcheson, A. Holmes, E. Yeatman, T. Green, and B. Stark, "MEMS inertial power generators for biomedical applications," Microsyst. Technol., vol. 12, no. 10-11, pp. 1079-1083, Sep. 2006.

[16] R. Elfrink, T. M. Kamel, M. Goedbloed, S. Matova, D. Hohlfeld, Y. van Andel, and R. van Schaijk, "Vibration energy harvesting with aluminum nitride-based piezoelectric devices," J. Micromechan. Microeng., vol. 19, no. 9, p. 094005, 2009.

[17] M. Renaud, K. Karakaya, T. Sterken, P. Fiorini, C. V. Hoof, and R. Puers, "Fabrication, modelling and characterization of MEMS piezoelectric vibration harvesters," Sensors Actuators A, Phys., vol. 145-146, pp. 380-386, 2008.

[18] [Online]. Available: http://www.perpetuum.com/

[19] [Online]. Available: http://www.enocean.com/

[20] V. Leonov and P. Florini, "Themal matching of thermoelectric energy scavenger with the ambient," in Proc. 5th Eur. Conf. Thermoelectrics, 2007, pp. 129-133.

[21] R. Vullers, R. van Schaijk, I. Doms, C. van Hoof, and R. Mertens, "Micropower energy harvesting," Solid-State Electron., vol. 53, no. 7, pp. 684-693, 2009.

[22] V. Leonov, T. Torfs, P. Fiorini, and C. van Hoof, "Thermoelectric converters of human warmth for self-powered wireless sensor nodes," IEEE Sensors J., vol. 7, no. 5, pp. 650-657, May 2007.

[23] P. Wright, "Energy harvesting in the human body (Implantable selfpowered sensors)," in Presentation, BWRC Summer Retreat, 2008.

[24] P. Favrat, P. Deval, and M. Declercq, "A high-efficiency cmos voltage doubler," IEEE J. Solid-State Circuits, vol. 33, no. 3, pp. 410-416, Mar. 1998.

[25] J. Dickson, "On-chip high-voltage generation in nmos integrated circuits using an improved voltage multiplier technique," IEEE J. SolidState Circuits, vol. JSSC-11, no. 3, pp. 374-378, Jun. 1976.

[26] J. Silva-Martinez, "A switched capacitor double voltage generator," in Proc. 37th Midwest Symp. Circuits and Systems, 1994, vol. 1, pp. $177-180$.

[27] J. Wu and K. Chang, "Mos charge pumps for low-voltage operation," IEEE J. Solid-State Circuits, vol. 33, no. 4, pp. 592-597, Apr. 1998.

[28] M. Kishi, H. Nemoto, T. Hamao, M. Yamamoto, S. Sudou, M. Mandai, and S. Yamamoto, "Micro thermoelectric modules and their application to wristwatches as an energy source," in Proc. 18th Int. Conf. Thermoelectric, 1999, pp. 301-307.

[29] I. Stark and M. Stordeur, "New micro thermoelectric devices based on bismuth telluride-type thin solid films," in Proc. 18th Int. Conf. Thermoelectric, 1999, pp. 465-472.

[30] M. Strasser, R. Aigner, C. Lauterbach, T. F. Sturm, M. Franosch, and G. Wachutka, "Micromachined CMOS thermoelectric generators as on-chip power supply," Sensors Actuators A, Phys., vol. 114, no. 2-3, pp. 362-370, 2004.

[31] [Online]. Available: http://www.poweredbythermolife.com

[32] R. Ferrigno, A. Stroock, T. Clark, M. Mayer, and G. Whitesides, "Membraneless vanadium redox fuel cell using laminar flow," J. Amer. Chem. Soc., vol. 124, no. 44, pp. 12 930-12 931, Nov. 2002.

[33] E. Choban, L. Markoski, A. Wieckowski, and P. Kenis, "Microfluidic fuel cell based on laminar flow," J. Power Sources, vol. 128, no. 1, pp. 54-60, Mar. 2004.

[34] S. Wolfson Jr, S. Gofberg, P. Prusiner, and L. Nanis, "The bioautofuel cell: A device for pacemaker power from direct energy conversion consuming autogenous fuel," Trans. Amer. Soc. Artif. Internal Organs, vol. 14, pp. 198-203, 1968.

[35] S. Kerzenmacher, J. Ducre, R. Zengerle, and F. von Stetten, "Energy harvesting by implantable abiotically catalyzed glucose fuel cells," $J$. Power Sources, vol. 182, no. 1, pp. 1-17, Jul. 2008.

[36] P. Malachesky, G. Holleck, F. McGovern, and R. Devarakonda, "Parametric studies of implantable fuel cell," in Proc. 7th Interso. Energy Convers. Eng. Conf., 1972, pp. 727-732.

[37] R. Drake, B. Kusserow, S. Messinger, and S. Matsuda, "A tissue implantable fuel cell power supply," ASAIO J., vol. 16, no. 1, pp. 199-205, 1970.

[38] N. Mano, F. Mao, and A. Heller, "Characteristics of a miniature compartment-less glucose- $\mathrm{O}_{2}$ biofuel cell and its operation in a living plant," J. Amer. Chem. Soc., vol. 125, no. 21, pp. 6588-6594, May 2003.

[39] R. Bullen, T. Arnot, J. Lakeman, and F. Walsh, "Biofuel cells and their development," Biosens. Bioelectron., vol. 21, no. 11, pp. 2015-2045, 2006.

[40] J. Phirani and S. Basu, "Analyses of fuel utilization in microfluidic fuel cell,” J. Power Sources, vol. 175, no. 1, pp. 261-265, Jan. 2008. 
[41] K. Murakawa, M. Kobayashi, O. Nakamura, and S. Kawata, "A wireless near-infrared energy system for medical implants," IEEE Eng. Med. Biol. Mag.,, vol. 18, no. 6, pp. 70-72, Nov./Dec. 1999.

[42] K. Goto, T. Nakagawa, O. Nakamura, and S. Kawata, "An implantable power supply with an optical rechargeable lithium battery," IEEE Trans. Biomed. Eng., vol. 48, no. 7, pp. 830-833, Jul. 2001.

[43] T. Oshita and R. Calderhead, Low Level Laser Therapy: A Practical Introduction. New York: Wiley, 1988.

[44] S. Suzuki, T. Katane, H. Saotome, and O. Saito, "Electric power-generating system using magnetic coupling for deeply implanted medical electronic devices," IEEE Trans. Magn., vol. 38, no. 5, pp. 3006-3008, Sep. 2002.

[45] S. Suzuki, T. Katane, H. Saotome, and O. Saito, "A proposal of electric power generating system for implanted medical devices," IEEE Trans. Magn., vol. 35, no. 5, pp. 3586-3588, Sep. 1999.

[46] E. Ngai, K. K. Moon, F. J. Riggins, and C. Y. Yi, "RFID research: An academic literature review (1995-2005) and future research directions," Int. J. Prod. Econ., vol. 112, no. 2, pp. 510-520, 2008.

[47] Activa RC Recharging System 37751 Medtronic.

[48] R. Sarpeshkar, Ultra Low Power Bioelectronics: Fundamentals, Biomedical Applications, and Bio-Inspired Systems. Cambridge, U.K.: Cambridge Univ. Press, 2010.

[49] K. Kalyanasundaram and M. Grätzel, "Artificial photosynthesis: Biomimetic approaches to solar energy conversion and storage," Current Opini. Biotechnol., vol. 21, no. 3, pp. 298-310, 2010.

[50] I. McConnell, G. Li, and G. W. Brudvig, "Energy conversion in natural and artificial photosynthesis," Chem. Biol., vol. 17, no. 5, pp. 434-447, 2010.

[51] M. Katterle, V. I. Prokhorenko, A. R. Holzwarth, and A. Jesorka, "An artificial supramolecular photosynthetic unit," Chem. Phys. Lett., vol. 447, no. 4-6, pp. 284-288, 2007.

[52] M. Grätzel, "Photoelectrochemical cells," Nature, vol. 414, no. 6861, pp. 338-344, 2001.

[53] T. Akin, K. Najafi, and R. Bradley, "A wireless implantable multichannel digital neural recording system for a micromachined sieve electrode," IEEE J. Solid-State Circuits, vol. 33, no. 1, pp. 109-118, Jan. 1998.

[54] C. Sauer, M. Stanacevic, G. Cauwenberghs, and N. Thakor, "Power harvesting and telemetry in CMOS for implanted devices," IEEE Trans. Circuits Syst. I, Reg. Papers, vol. 52, no. 12, pp. 2605-2613, Dec. 2005.

[55] B. Lenaerts and R. Puers, "An inductive power link for a wireless endoscope," Biosens. Bioelectron., vol. 22, no. 7, pp. 1390-1395, 2007.

[56] K. Silay, D. Dondi, L. Larcher, M. Declercq, L. Benini, Y. Leblebici, and C. Dehollain, "Load optimization of an inductive power link for remote powering of biomedical implants," in Proc. IEEE Int. Symp. Circuits and Systems, May 2009, pp. 533-536.

[57] M. Catrysse, B. Hermans, and R. Puers, "An inductive power system with integrated bi-directional data-transmission," Sens. Actuators A, Phys., vol. 115, no. 2-3, pp. 221-229, Sep. 2004.

[58] J. Parramon, P. Doguet, D. Marin, M. Verleyssen, R. Munoz, L. Leija, and E. Valderrama, "ASIC-based batteryless implantable telemetry microsystem for recording purposes," in Proc. IEEE 19th Annu. Int. Conf. Eng. Med. Biol. Soc., 1997, vol. 5, pp. 2225-2228.

[59] G. Gudnason, E. Bruun, and M. Haugland, "A chip for an implantable neural stimulator," Analog Integr. Circuits Signal Process., vol. 22, no. 1 , pp. 81-89, 2000.

[60] B. Smith, Z. Tang, M. Johnson, S. Pourmehdi, M. Gazdik, J. Buckett, and P. Peckham, "An externally powered, multichannel, implantable stimulator-telemeter for control of paralyzed muscle," IEEE Trans. Biomed. Eng., vol. 45, no. 4, pp. 463-475, Apr. 1998.

[61] M. Ahmadi and G. Jullien, "A wireless-implantable microsystem for continuous blood glucose monitoring," IEEE Trans. Biomed. Circuits Syst., , vol. 3, no. 3, pp. 169-180, Jun. 2009.

[62] B. Lenaerts and R. Puers, Omnidirectional Inductive Powering for Biomedical Implants. New York: Springer, 2009.

[63] N. Sokal, "Class-E RF power amplifiers," $Q E X$, pp. 9-20, Jan./Feb. 2001.

[64] M. Ghovanloo and K. Najafi, "A high data transfer rate frequency shift keying demodulator chip for the wireless biomedical implants," in Proc. 45th Midwest Symp. Circuits and Systems, 2002, vol. 3, pp. 433-436.

[65] A. Poon, S. O'Driscoll, and T. Meng, "Optimal operating frequency in wireless power transmission for implantable devices," in Proc. IEEE 29th Annu. Int. Conf. EMBS, 2007, pp. 5673-5678.

[66] D. Pozar, Microwave Engineering, 3rd ed. New York: Wiley, 2005.

[67] S. Gabriel, R. Lau, and C. Gabriel, "The dielectric properties of biological tissues: III. Parametric models for the dielectric spectrum of tissues," Phys. Med. Biol., vol. 41, pp. 2271-2293, 1996.

[68] A. Poon, S. O'Driscoll, and T. Meng, "Optimal frequency for wireless power transmission into dispersive tissue," IEEE Trans. Antennas Propag., vol. 58, no. 5, pp. 1739-1750, May 2010.

[69] Visible Human Server. [Online]. Available: http://visiblehuman. epfl.ch/

[70] A. Poon, S. O'Driscoll, and T. Meng, "A mm-sized implantable power receiver with adaptative link compensation," in Proc. IEEE Tech. Dig. Int. Solid-State Circuits Conf., 2009, pp. 294-295, 295a.

[71] IEEE Standard for Safety Levels with Respect to Human Exposure to Radio Frequency Electromagnetic Fields, $3 \mathrm{kHz}$ to $3 \mathrm{Ghz}$, IEEE Std. C95-1, 1999.

[72] Int. Comm. Non-Ionizing Radation Protection Std., Guidelines for limiting exposure to time-varying electric, magnetic and electromagnetic fields (up to $300 \mathrm{GHz}$ )

[73] S. Michaelson, "Health implications of exposure to radiofrequency/microwave energies," British J. Ind. Med., vol. 39, pp. 105-119, 1982.

[74] P. Bernardi, M. Cavagnaro, S. Pisa, and E. Piuzzi, "Specific absorption rate and temperature increases in the head of a cellular-phone user," IEEE Trans. Microw. Theory Tech., vol. 48, no. 7, pp. 1118-1126, Jul. 2000.

[75] D. Hermann and K. Hossmann, "Neurological effects of microwave exposure related to mobile communication," J. Neurolog. Sci., vol. 152, no. 1, pp. 1-14, 1997.

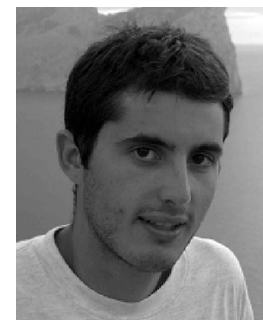

plantable biosensors.
Jacopo Olivo received the M.Sc. degree in electrical engineering from the University of Bologna, Bologna, Italy, in 2008 and is currently pursuing the $\mathrm{Ph} . \mathrm{D}$. degree at the Integrated System Laboratory, EPFL, Lausanne, Switzerland.

During his master's project, he became involved in the field of biosensors concerning the design and development of an integrable system for electrochemical measurements in point-of-care applications for personalized medicine. His research interest focuses on energy scavenging techniques for im-

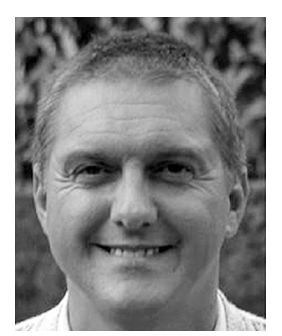

Sandro Carrara (M'08) received the M.Sc. degree in physics from the University of Genoa, Genoa, Italy, and the Ph.D. degree in biochemistry and biophysics from Padua University.

Currently, he is Scientist and Lecturer at EPFL, Lausanne, Switzerland. He also is Professor of Nano-Bio-Sensing and Micro/nano Interfaces at the University of Genoa. He has more than 80 international publications and 10 patents. $\mathrm{He}$ is an Associate Editor of the IEEE TRANSACTIONS ON BIOMEDICAL CIRCUITS AND SYSTEMS and IEEE SENSORS JOURNAL. His main scientific interest is on electrical phenomena mediated by nanostructured molecular thin films. Currently, he is focusing on the development of protein and DNA-based complementary metal-oxide semiconductor chips. He is referee of 11 international journals and is an internationally esteemed expert of the evaluation panel of the Academy of Finland in a research program for the years 2010-2013.

Dr. Carrara is also the Chair of a Workshop on Nano-Bio-Sensing paradigms and applications (Luzern, 2009) and Technical Program Co-Chair of the International Symposium on Medical Information and Communication Technology (Montreux, 2011). He has been a Professor of Biophysics at the University of Genoa and in Nanobiotechnology at the University of Bologna, Bologna, Italy $\mathrm{He}$ is on the Board of the IEEE International Conference on Biomedical Circuits and Systems (Beijing, 2009; Cyprus, 2010). In 1996, he won a NATO Advanced Research prize for his original contribution to the role of nano-particles size in single-electron conductivity. More recently, he was awarded the NanoEurope Symposium in 2009 (Rapperswil), and at the IEEE International Conference PRIME with the bronze leaf prize (2010 - Berlin) and the golden leaf prize (2009 - Cork). From 1997 to 2000, he was a member of an international committee at the ELETTRA Synchrotron. From 2000 to 2003, he was scientific leader of a National Research Program (PNR) in the field of nanobiotechnology. In 2006, he received the best 2006 referees' award from the Biosensor and Bioelectronics journal. 


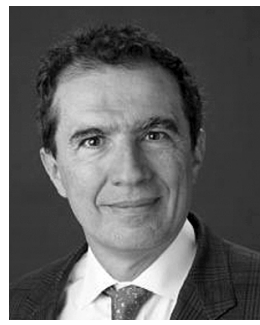

Giovanni De Micheli (F'94) is Professor and Director of the Institute of Electrical Engineering and of the Integrated Systems Centre, EPFL, Lausanne, Switzerland. He is Program Leader of the Nano-Tera.ch program. His research interests include several aspects of design technologies for integrated circuits and systems, such as synthesis for emerging technologies, networks on chips, and 3-D integration. $\mathrm{He}$ is also interested in heterogeneous platform design, including electrical components biomedical information. and biosensors as well as in data processing of

Prof. De Micheli is the recipient of the 2003 IEEE Emanuel Piore Award for contributions to computer-aided synthesis of digital systems. He is a Fellow of ACM. He received the Golden Jubilee Medal for outstanding contributions to the IEEE CAS Society in 2000. He received the 1987 D. Pederson Award for the best paper on the IEEE TRANSACTIONS ON COMPUTER-AIDED DESIGN/ ICAS; two Best Paper Awards at the Design Automation Conference in 1983 and in 1993; and a Best Paper Award at the DATE Conference in 2005. He has served IEEE in several capacities, namely, Division 1 Director (2008-2009), Co-Founder and President Elect of the IEEE Council on EDA (2005-2007), President of the IEEE CAS Society (2003), and Editor-in-Chief of the IEEE TRANSACTIONS ON COMPUTER-AIDED DESIGN/ICAS (1987-2001). He is and has been chair of several conferences, including DATE (2010), pHealth (2006), VLSI SOC (2006), DAC (2000), and ICCD (1989). 